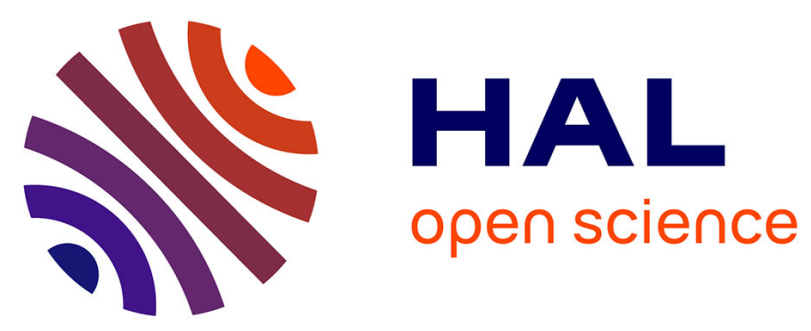

\title{
Melatonin and hydroxytyrosol protect against oxidative stress related to the central nervous system after the ingestion of three types of wine by healthy volunteers
}

Javier Marhuenda, Sonia Medina, Pedro Martínez-Hernández, Simón Arina, Pilar Zafrilla, Juana Mulero, Camille Oger, Jean-Marie Galano, Thierry

Durand, Federico Ferreres, et al.

\section{To cite this version:}

Javier Marhuenda, Sonia Medina, Pedro Martínez-Hernández, Simón Arina, Pilar Zafrilla, et al.. Melatonin and hydroxytyrosol protect against oxidative stress related to the central nervous system after the ingestion of three types of wine by healthy volunteers. Food and Function, 2017, 8 (1), pp.64-74. 10.1039/c6fo01328g . hal-02594016

\section{HAL Id: hal-02594016 https://hal.science/hal-02594016}

Submitted on 15 May 2020

HAL is a multi-disciplinary open access archive for the deposit and dissemination of scientific research documents, whether they are published or not. The documents may come from teaching and research institutions in France or abroad, or from public or private research centers.
L'archive ouverte pluridisciplinaire HAL, est destinée au dépôt et à la diffusion de documents scientifiques de niveau recherche, publiés ou non, émanant des établissements d'enseignement et de recherche français ou étrangers, des laboratoires publics ou privés. 


\title{
Melatonin and hydroxytyrosol protect against oxidative stress related to the central nervous system after the ingestion of three types of wine by healthy volunteers
}

\author{
Javier Marhuenda, a,b Sonia Medina, ${ }^{\text {a }}$ Pedro Martínez-Hernández, ${ }^{c, d}$ Simón Arina, ${ }^{d}$ \\ Pilar Zafrilla, ${ }^{\mathrm{b}}$ Juana Mulero, ${ }^{\mathrm{b}}$ Camille Oger, ${ }^{\mathrm{e}}$ Jean-Marie Galano, ${ }^{\mathrm{e}}$ Thierry Durand, ${ }^{\mathrm{e}}$ \\ Federico Ferreres ${ }^{a}$ and Angel Gil-Izquierdo*a
}

\begin{abstract}
Adrenic acid (AdA) and docosahexaenoic acid (DHA) peroxidation produces $\mathrm{F}_{2}$-dihomo-IsoPs and neuroprostanes, which have been related to oxidative damage in the central nervous system. Besides polyphenols, melatonin (MEL) and hydroxytyrosol (OHTyr) could be partly responsible for the antioxidant benefits of red wine (excluding colon derivatives). In order to elucidate whether these compounds are responsible for the protective antioxidant effects of red wine, a double-blind, crossover, placebocontrolled in vivo study - involving the intake of red wines and their native musts by healthy volunteers was performed. The urinary metabolites decreased after the administration of red wines, to a greater extent than after the intake of their corresponding musts or ethanol. Melatonin is the most effective compound that protects adrenic acid from oxidative attack, judged by the reduction in the formation of $\mathrm{F}_{2}$-dihomo-isoprostanes. Similarly, hydroxytyrosol, being the most effective bioactive compound in reducing the formation of $F_{3}$-neuroprostanes $n-6$ DPA and $F_{4}$-neuroprostanes, protected docosahexaenoic and eicosapentaenoic acids from oxidative attack.
\end{abstract}

\section{Introduction}

Lipid peroxidation products have been investigated in order to determine their use as biomarkers of the oxidative status in the human body. Linolenic acid (LNA), arachidonic acid (AA), adrenic acid (AdA), and docosahexanoic acid (DHA) are commonly-studied fatty acids ${ }^{1,2}$ which can give rise to phytoprostanes (PhytoPs), ${ }^{3}$ isoprostanes (IsoPs), ${ }^{1,2} \mathrm{~F}_{2}$-dihomo-isoprostanes ( $\mathrm{F}_{2}$-dihomo-IsoPs), and neuroprostanes (NeuroPs), ${ }^{2}$ respectively. IsoPs have been established as general oxidative stress biomarkers in humans. ${ }^{4}$ Moreover, $\mathrm{F}_{2}$-dihomo-IsoPs have been related to early brain damage in Rett syndrome, and

\footnotetext{
${ }^{a}$ Research Group on Quality, Safety and Bioactivity of Plant Foods, Department of Food Science and Technology, CEBAS (CSIC), P.O. Box 164, 30100 Campus University Espinardo, Murcia, Spain. E-mail: smescudero@cebas.csic.es, angelgil@cebas.csic.es; Fax: +34 968396213; Tel: +34 968396200 ext. 6253, +34968396200 ext. 6363

${ }^{b}$ Department of Food Technology and Nutrition, Catholic University of San Antonio, Murcia 30107, Spain

${ }^{c}$ Lab of Clinical Analysis, University Hospital Virgen de la Arrixaca, Murcia, Spain ${ }^{d}$ Bodegas Baigorri S.A.U., Ctra. Vitoria-Logroño Km. 53, 01307 Samaniego, Álava, Spain

${ }^{e}$ Institut des Biomolécules Max Mousseron (IBMM), UMR 5247 - CNRS - University of Montpellier - ENSCM, Faculty of Pharmacy, Montpellier, France
}

to white matter injury, ${ }^{5}$ in particular, because of their specific location in neural membranes. ${ }^{2}$

The Mediterranean Diet (MD) has been shown to exert several benefits with regard to the maintenance of the redox balance in humans. Polyphenols have been thought to be mainly responsible for the antiradical effects of the foodstuffs included in the MD. ${ }^{6}$ Wine is a representative alcoholic component of the MD, considered responsible for the "French Paradox". 7 In fact, ethanol exhibits antioxidant capacity in vivo. ${ }^{7}$ Therefore, alcohol could be partially responsible for the effects of red wine. Moreover, red wine polyphenols have demonstrated an in vivo and in vitro antioxidant capacity. ${ }^{6,8}$ Nevertheless, despite these beneficial effects, polyphenols have very-low in vivo and in vitro bioavailability. ${ }^{1,9}$ Aside from the more-deeply-studied polyphenols, melatonin (MEL), hydroxytyrosol (OHTyr), and their metabolites arising from the metabolic activity of the colonic microflora (such as homovanillic alcohol and homovanillic acid), among other known and/or unknown compounds, could be partly responsible for the antioxidant benefits of red wine. ${ }^{10,11}$ In turn, MEL could be responsible for the health effects of the Mediterranean diet. ${ }^{12}$ Such bioactive compounds act as radical scavengers, regulating the oxidation status of organisms. ${ }^{10}$ Moreover, both compounds are able to go through physiological barriers, in 
particular the blood-brain barrier (BBB). Therefore, their neuroprotective capacity has been related previously. ${ }^{13}$

The current research aims to elucidate, for the first time, the neuroprotection against oxidative stress provided by red wine, measured by urinary neuroprostanes and dihomoisoprostanes.

\section{Materials and methods}

\section{Chemicals and reagents}

HPLC-grade ACN and methanol were purchased from Scharlau Chemie (Barcelona, Spain). Ultrapure water (Milli-Q) was obtained from a Milli-Q Gradient A10 system (Millipore, Bedford, MA). $\mathrm{F}_{4}$-NeuroPs and $\mathrm{F}_{3}$-NeuroPs n-6 DPA including $4(R S)-\mathrm{F}_{4 \mathrm{t}}-\mathrm{NeuroP}, \quad \mathrm{d}_{4}-4(R S)-\mathrm{F}_{4 \mathrm{t}}-$ NeuroP, $10-$ epi-10- $\mathrm{F}_{4 \mathrm{t}}-$ NeuroP, $\mathrm{d}_{4}-10-$ epi-10- $\mathrm{F}_{4 \mathrm{t}}-$ NeuroP, 10- $\mathrm{F}_{4 \mathrm{t}}-\mathrm{NeuroP}, \mathrm{d}_{4}-10-\mathrm{F}_{4 \mathrm{t}}-$ NeuroP, $4-\mathrm{F}_{4 \mathrm{t}^{-}}$ NeuroP, 4-epi-4- $\mathrm{F}_{3 \mathrm{t}}-\mathrm{NeuroP}$, and $4-\mathrm{F}_{3 \mathrm{t}}-\mathrm{NeuroP}$ and dihomo-

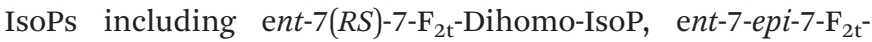
Dihomo-IsoP, 17- $\mathrm{F}_{2 \mathrm{t}}$-Dihomo-IsoP, and 17-epi-17- $\mathrm{F}_{2 \mathrm{t}}-$ DihomoIsoP were synthesized by Durand's research team at the Institut des Biomolecules Max Mousseron (IBMM) (Montpellier, France). ${ }^{14} \beta$-Glucuronidase, type $\mathrm{H} 2$ from Helix pomatia, and BIS-TRIS (bis-(2-hydroxyethyl)-amino-tris(hydroxymethyl)-methane) were from Sigma-Aldrich (St Louis, MO, USA). The Strata X-AW, $100 \mathrm{mg} 3 \mathrm{~mL}^{-1} \mathrm{SPE}$ cartridges were from Phenomenex (Torrance, CA, USA).

\section{Red wine and must samples in this clinical and nutritional trial}

The description of red wines and their primary musts were detailed in our previous study. ${ }^{15}$ The red wines were provided by the Baigorri winery (Bodegas Baigorri S.A.U, Samaniego, Álava). Three different wines were selected in order to compare different vinification and aging procedures: "Baigorri carbonic maceration 2010", "Baigorri aged 2007" and "Baigorri high expression 2010". For their correct maintenance, they were stored at between $12{ }^{\circ} \mathrm{C}$ and $14^{\circ} \mathrm{C}$ after bottling. The musts analyzed during the current assay were stored at $-20{ }^{\circ} \mathrm{C}$ after the harvest of the grapes, so that the fermentation process did not begin. They were the original grape juices used for the winemaking procedure of each wine. This permitted determination of the differences between the wines that arose from the distinct winemaking processes, hence avoiding any differences in the grape variety or harvesting procedure from must to wine.

\section{Study design}

The present study was previously approved by the Bioethics Committee of the Catholic University San Antonio of Murcia (UCAM). The characteristics of the study have been described in our previous research. ${ }^{15}$ The study included a total of 18 $(N=18)$ healthy female volunteers, between 18 and 27 years old (characteristics were described in our previous research). ${ }^{15}$ Importantly, all individuals in this study were nonsmokers and during the study the women were not in their menstrual days. Informed and signed consent of each individual involved in the trial was obtained. The development of the study was double-blind, crossover and placebo-controlled, carried out in four stages. At the beginning of each stage, the volunteers $(N=18)$ were divided into two equal groups $\left(N_{1}=9\right.$ and $\left.N_{2}=9\right)$ in order to facilitate the crossover of the study. The structure of the stages consisted of 48 hours of urine collection since the beginning of the treatment, followed by a 72 hours washout period. Finally, after the washout period the crossover was developed, collecting the urine of the volunteers along the following 48 hours. Afterwards, each stage was in turn separated by washout periods of 72 hours too. The graphical distribution of the different stages developed in the present study has been described in Fig. 1.

Urine samples were obtained equally in all the stages of the study (graphically represented in Fig. 1). At 0 hours, the first urine in the morning was obtained both before and after the crossover. Additionally, samples were collected from 0 to 48 hours in order to establish the in vivo effects of the intake of the different beverages. Importantly, the data obtained are expressed in $\mu \mathrm{g}$ per $24 \mathrm{~h}$ in order to facilitate the comparison with the previously reported data.

\section{Sample preparation for neuroprostane and $F_{2}$-dihomo- isoprostane analysis}

The extraction of NeuroPs and $\mathrm{F}_{2}$-dihomo-IsoPs from urine was carried out according to Medina et al. (2015). ${ }^{16}$ Calibration-standard stock solutions of NeuroPs and $\mathrm{F}_{2}$-dihomo-IsoPs were diluted with methanol : water $(1: 1, \mathrm{v}: \mathrm{v})$ to obtain the appropriate working solutions. All solutions were stored at $-80{ }^{\circ} \mathrm{C}$. The concentrations of NeuroPs and $\mathrm{F}_{2}$-dihomo-IsoPs were calculated from standard curves prepared each day.

For the enzymatic hydrolysis, to remove the glucuronide and sulfate conjugates, $1 \mathrm{~mL}$ of urine was added to $250 \mu \mathrm{L}$ of $0.1 \mathrm{M}$ acetate buffer ( $\mathrm{pH} 4.9$ ) and $55 \mu \mathrm{L}$ of $\beta$-glucuronidase from Helix pomatia. The mixture was incubated at $37^{\circ} \mathrm{C}$ in a thermal block for two hours. After this step, protein precipitation was carried out with $500 \mu \mathrm{L}$ of methanol/chlorhydric acid $(200 \mu \mathrm{M})$. Then, the samples were centrifuged at $10000 \mathrm{~g}$ for $5 \mathrm{~min}^{16}$

One milliliter of the supernatant was subjected to solid phase extraction (SPE) using a Strata X-AW cartridge (100 mg/3 mL), according to Medina et al. (2015). ${ }^{16}$ Briefly, samples that had been diluted in $2 \mathrm{~mL}$ of methanol and $1.25 \mathrm{~mL}$ of BIS-TRIS buffer were passed through the previously-conditioned and equilibrated cartridges. The analytes were eluted with $1 \mathrm{~mL}$ of methanol and dried under vacuum using a SpeedVac concentrator (Savant SPD121P, Thermo Scientific, MA, USA). The dry extracts were reconstituted with the $\mathrm{A}: \mathrm{B} \quad(90: 10, \mathrm{v}: \mathrm{v})$ mobile phases and filtered through a $0.45 \mu \mathrm{m}$ filter (Millipore, MA, USA). The samples were injected and analyzed by using UHPLC-QqQ-MS/MS. 


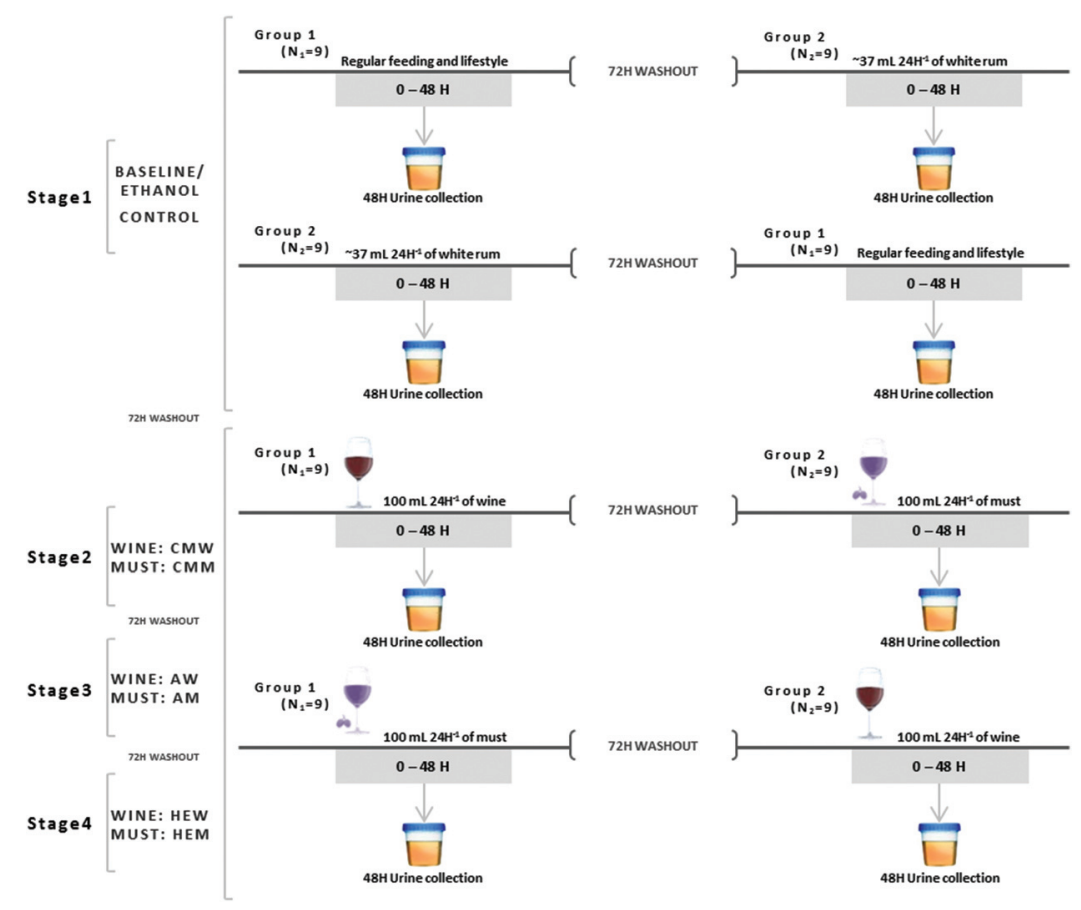

Fig. 1 Graphical representation of the in vivo assay, divided into four stages. Stages 2, 3, and 4 were similar but the beverage drank changed between stages. A period of 72 hours was included between stages and before the crossover. MCW/MCM: carbonic maceration wine/must; AW/AM: aged wine/must; HEW/HEM: high expression wine/must.

\section{UHPLC-QqQ-MS/MS analysis of neuroprostanes and $\mathrm{F}_{2}$-dihomo-isoprostanes}

The NeuroPs $/ \mathrm{F}_{2}$-dihomo-IsoPs were separated using a UHPLC system coupled to a 6460 triple quadrupole tandem mass spectrometer (Agilent Technologies, Waldbronn, Germany).

The urinary NeuroPs and $\mathrm{F}_{2}$-dihomo-IsoPs were extracted from the $24 \mathrm{~h}$ urines. ${ }^{16}$ Chromatographic separation was carried out on an ACQUITY BEH $\mathrm{C}_{18}$ column $(2.1 \times 50 \mathrm{~mm}$, $1.7 \mu \mathrm{m}$ pore size) (Waters, MA, USA). The column temperatures were $6{ }^{\circ} \mathrm{C}$ (left) and $6{ }^{\circ} \mathrm{C}$ (right). Sample analysis was carried out as reported by Medina et al. (2015). The multiple reaction monitoring (MRM) mode was employed using the negative electrospray ionization (ESI) mode. The mobile phases A (water) and B (methanol) contained $0.01 \%$ acetic acid (v:v).

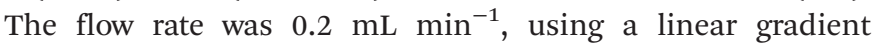
scheme $(t ; \% B)$ : (0.0; 60.00), (7.00; 70.00), (7.01; 90.00), (10.00; $90.00)$, and $(10.01 ; 60.00)$.

The injection volume was $20 \mu \mathrm{L}$ in UHPLC-QqQ-MS/MS. The operating conditions for the MS were as follows: gas flow $8 \mathrm{~L} \mathrm{~min}^{-1}$, nebulizer $30 \mathrm{psi}$, capillary voltage $4000 \mathrm{~V}$, nozzle voltage $1000 \mathrm{~V}$, gas temperature $325{ }^{\circ} \mathrm{C}$, sheath gas temperature $350{ }^{\circ} \mathrm{C}$, and jetstream gas flow $12 \mathrm{~L} \mathrm{~min}^{-1}$. The time for a single analysis was $10.01 \mathrm{~min}$. The MS parameters fragmentor (ion optics) and collision energy were optimized for each compound to generate the most abundant product ions. Data acquisition and processing were performed using MassHunter software version B.04.00 (Agilent Technologies, Walbronn, Germany). The urinary amounts of the NeuroPs $/ \mathrm{F}_{2}$-dihomoIsoPs were calculated from the area ratio of the ion peaks of the compounds to those of the corresponding standards (expressed as ng of analytes excreted over $24 \mathrm{~h}$ ).

\section{Analysis of melatonin and phenolics in wines and musts}

The methods used for the characterization of the samples were described in our previous study. ${ }^{15}$ The different phenolic compounds detected in the samples of wine and must were identified by their UV-Vis spectra and chromatographic comparison with authentic commercial markers. ${ }^{17,18}$

For the determination of OHTyr and its metabolites, a UHPLC coupled to a 6460 QqQ-MS/MS (Agilent Technologies, Waldbronn, Germany) was used, following the method designed by Domínguez-Perles et al. (2015). ${ }^{19}$

For the analysis of MEL and serotonin, the extraction procedure for the wines and musts was as previously described. ${ }^{20}$ The separation and determination of MEL and serotonin were performed using a UHPLC coupled to a 6460 QqQ-MS/MS (Agilent Technologies, Waldbronn, Germany) and a Waters Acquity UHPLC BEH C $\mathrm{C}_{18} 1.7 \mu \mathrm{m} 2.1 \times 50 \mathrm{~mm}$ column.

\section{Statistical analysis}

The analysis of variance (ANOVA; Duncan) was applied to establish significant differences between the means obtained during the fermentation process. A probability value of $p<0.05$ was adopted as the criteria for significant differences.

To determine the individual involvement of the different bioactive compounds and the total phenolic content of lipid peroxidation products, simple regression analysis $\left(R^{2}\right)$ was performed. This statistical method allows one to know about 
the individual relationship of each of the bioactive compounds and TPC with the plasmatic concentration of lipid peroxidation products. However, since both wines and musts are matrices composed of various compounds of interest, it is essential to study all relationships simultaneously. Therefore, the results obtained after determining the simple regression were contrasted with multiple regression analysis (stepwise mode), in order to establish a real-based relationship. These analyses were performed with SPSS version 21 software (SPSS Inc., Chicago, IL, USA).

\section{Results}

\section{Qualitative and quantitative analyses of melatonin and phenolics in wines and musts}

The results related to the content of bioactive compounds of the different wine and must samples were reported in our previous study. ${ }^{15}$ As a resume, the results are detailed above with the aim to facilitate the comprehension of the present study. The concentrations of the different bioactive compounds are detailed in Table 1 describing the content of MEL, hydroxytyrosol (OHTyr) and their metabolites, and Table 2 showing the content of phenolic compounds.

Regarding MEL, the musts contained similar and very low amounts of this compound, compared to the wines. The MEL concentration of the carbonic maceration must (CMM) was

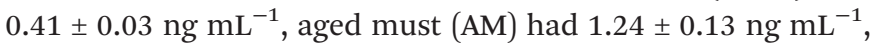
and high expression must (HEM) had $0.03 \pm 0.004 \mathrm{ng} \mathrm{mL}^{-1}$. The MEL concentration found in carbonic maceration wine (CMW) $\left(161.83 \pm 7.14 \mathrm{ng} \mathrm{mL}^{-1}\right)$ was higher than the other two wines $(p<0.01)$ : the aged wine (AW) $\left(26.31 \pm 1.35 \mathrm{ng} \mathrm{mL}^{-1}\right)$ and the high expression wine (HEW) $\left(19.63 \pm 1.14 \mathrm{ng} \mathrm{mL} \mathrm{mL}^{-1}\right)$ had similar concentrations $(p>0.05)$.

Red wine is one of the major dietary sources of OHTyr. The analysis of OHTyr and its metabolites yielded two metabolites

Table 1 Characterization of bioactive compounds of red wines and musts and the white rum ethanol content

\begin{tabular}{|c|c|c|c|c|c|}
\hline & \multirow[b]{2}{*}{ Melatonin $\left(\mathrm{ng} \mathrm{mL}^{-1}\right)$} & \multirow[b]{2}{*}{ Ethanol (g per dose $)^{a}$} & \multicolumn{3}{|c|}{ Hydroxytyrosol metabolites $\left(\mu \mathrm{g} \mathrm{mL}^{-1}\right)$} \\
\hline & & & Homovanillic acid & Homovanillic alcohol & Hydroxytyrosol \\
\hline WR & - & 4.14 & - & - & - \\
\hline CMW & $161.83 \pm 7.14^{\mathrm{a}}$ & 4.14 & $83.46 \pm 13.59^{c}$ & $189.23 \pm 8.71^{\mathrm{a}}$ & $16.13 \pm 2.98^{\mathrm{b}}$ \\
\hline CMM & $0.41 \pm 0.039^{\mathrm{d}}$ & - & $130.76 \pm 1.32^{\mathrm{a}}$ & $14.63 \pm 0.17^{c}$ & $0.53 \pm 0.05^{\mathrm{c}}$ \\
\hline $\mathrm{AW}$ & $26.31 \pm 1.35^{\mathrm{b}}$ & 4.14 & $74.38 \pm 0.68^{\mathrm{c}}$ & $65.51 \pm 1.31^{\mathrm{b}}$ & $29.65 \pm 0.46^{\mathrm{a}}$ \\
\hline $\mathrm{AM}$ & $1.24 \pm 0.13^{\mathrm{c}, \mathrm{d}}$ & - & $112.41 \pm 3.12^{\mathrm{a}, \mathrm{b}}$ & $16.22 \pm 1.02^{\mathrm{c}}$ & $0.96 \pm 0.09^{c}$ \\
\hline HEW & $19.63 \pm 1.14^{\mathrm{b}}$ & 4.14 & $75.94 \pm 7.29^{c}$ & $51.56 \pm 6.27^{\mathrm{b}}$ & $35.11 \pm 2.51^{\mathrm{a}}$ \\
\hline HEM & $0.03 \pm 0.004^{\mathrm{d}}$ & - & $101.04 \pm 2.21^{\mathrm{a}, \mathrm{b}}$ & $60.59 \pm 1.31^{b}$ & $0.54 \pm 0.03^{c}$ \\
\hline
\end{tabular}

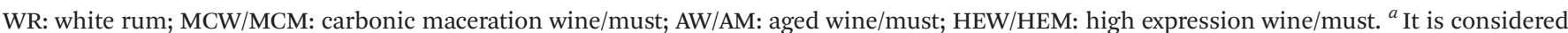
as the total dose ingested over 48 hours: $74 \mathrm{~mL}$ of white rum and $200 \mathrm{~mL}$ of wine and must.

Table 2 Characterization of polyphenolic compounds of red wines and musts

\begin{tabular}{|c|c|c|c|c|c|c|}
\hline & CMW & CMM & AW & $\mathrm{AM}$ & HEW & HEM \\
\hline Delphinidin-3-O-glucoside & $55.97 \pm 2.18^{\mathrm{a}}$ & $12.11 \pm 0.56^{\mathrm{c}, \mathrm{d}}$ & $39.81 \pm 0.48^{\mathrm{b}}$ & $12.96 \pm 1.10^{\mathrm{c}, \mathrm{d}}$ & $11.36 \pm 0.47^{\mathrm{d}}$ & $14.63 \pm 1.14^{\mathrm{c}}$ \\
\hline Cyanidin-3-O-glucoside & $2.45 \pm 0.05^{\mathrm{b}, \mathrm{c}}$ & $4.03 \pm 0.17^{\mathrm{b}}$ & $3.44 \pm 0.09^{\mathrm{b}, \mathrm{c}}$ & $3.69 \pm 0.08^{\mathrm{b}}$ & $0.60 \pm 0.04^{\mathrm{c}}$ & $7.29 \pm 0.88^{\mathrm{a}}$ \\
\hline Petunidin-3-O-glucoside & $54.73 \pm 1.26^{\mathrm{a}}$ & $9.13 \pm 0.59^{d}$ & $30.21 \pm 0.27^{b}$ & $9.12 \pm 0.98^{\mathrm{d}}$ & $8.17 \pm 0.20^{\mathrm{d}}$ & $13.85 \pm 0.95^{\mathrm{c}}$ \\
\hline Peonidin-3-O-glucoside & $11.77 \pm 1.04^{\mathrm{b}}$ & $7.36 \pm 1.52^{\mathrm{c}}$ & $10.96 \pm 0.35^{\mathrm{b}}$ & $7.38 \pm 0.74^{\mathrm{c}}$ & $3.37 \pm 0.04^{\mathrm{d}}$ & $14.66 \pm 1.39^{\mathrm{a}}$ \\
\hline Malvidin-3-O-glucoside & $236.87 \pm 10.00^{\mathrm{a}}$ & $35.80 \pm 2.30^{\mathrm{d}}$ & $90.10 \pm 5.09^{b}$ & $38.53 \pm 20.00^{\mathrm{d}}$ & $35.19 \pm 0.61^{c}$ & $74.16 \pm 3.29^{\mathrm{d}}$ \\
\hline Total anthocyanins & $361.79 \pm 11.27^{\mathrm{a}}$ & $68.43 \pm 3.71^{\mathrm{d}}$ & $174.53 \pm 5.98^{\mathrm{b}}$ & $71.68 \pm 3.25^{\mathrm{d}}$ & $58.68 \pm 0.74^{\mathrm{c}}$ & $124.59 \pm 4.56^{\mathrm{d}}$ \\
\hline Caftaric acid & $45.09 \pm 4.52^{\mathrm{b}, \mathrm{c}}$ & $0.59 \pm 0.02^{\mathrm{d}}$ & $48.81 \pm 0.03^{\mathrm{a}, \mathrm{b}}$ & $0.31 \pm 0.02^{\mathrm{d}}$ & $55.70 \pm 4.73^{\mathrm{a}}$ & $2.35 \pm 0.12^{\mathrm{d}}$ \\
\hline$p$-Coumaric acid & $1.30 \pm 0.07^{\mathrm{c}}$ & ND & $10.59 \pm 0.73^{b}$ & ND & $14.42 \pm 1.04^{\mathrm{a}}$ & ND \\
\hline Fertaric acid & $0.76 \pm 0.04^{\mathrm{c}}$ & ND & $2.40 \pm 0.08^{\mathrm{b}}$ & ND & $5.20 \pm 0.30^{\mathrm{a}}$ & ND \\
\hline Coutaric acid & $40.82 \pm 1.75^{\mathrm{a}}$ & $0.39 \pm 0.06^{\mathrm{d}}$ & $13.69 \pm 0.32^{c}$ & $0.28 \pm 0.02^{\mathrm{d}}$ & $20.54 \pm 0.71^{\mathrm{b}}$ & $1.13 \pm 0.10^{\mathrm{d}}$ \\
\hline Total hydroxycinnamic derivatives & $87.96 \pm 6.39^{\mathrm{a}}$ & $0.98 \pm 0.08^{\mathrm{c}}$ & $75.50 \pm 1.15^{\mathrm{b}}$ & $0.59 \pm 0.04^{\mathrm{c}}$ & $95.85 \pm 6.77^{\mathrm{a}}$ & $3.48 \pm 0.22^{\mathrm{c}}$ \\
\hline Myricetin-3-O-glucoside & $3.96 \pm 0.06^{\mathrm{a}}$ & $1.06 \pm 0.04^{\mathrm{c}}$ & $4.21 \pm 0.23^{\mathrm{a}}$ & $1.00 \pm 0.04^{\mathrm{c}}$ & $2.84 \pm 0.26^{\mathrm{b}}$ & $1.22 \pm 0.05^{\mathrm{c}}$ \\
\hline Quercetin-3-O-glucoside & $2.33 \pm 0.21^{\mathrm{c}}$ & $0.63 \pm 0.10^{\mathrm{d}}$ & $3.36 \pm 0.12^{\mathrm{b}}$ & $0.60 \pm 0.09^{\mathrm{d}}$ & $6.88 \pm 0.25^{\mathrm{a}}$ & $0.73 \pm 0.12^{\mathrm{d}}$ \\
\hline Quercetin-3-O-rutinoside & $33.37 \pm 1.88^{\mathrm{b}}$ & $2.15 \pm 0.14^{\mathrm{d}}$ & $24.93 \pm 3.32^{c}$ & $2.03 \pm 0.14^{\mathrm{d}}$ & $49.77 \pm 5.24^{\mathrm{a}}$ & $2.49 \pm 0.17^{\mathrm{d}}$ \\
\hline Kaempferol-3-O-glucoside & $10.19 \pm 1.27^{\mathrm{b}}$ & $2.54 \pm 0.13^{\mathrm{d}}$ & $6.49 \pm 0.34^{\mathrm{c}}$ & $2.39 \pm 0.12^{\mathrm{d}}$ & $18.82 \pm 1.28^{\mathrm{a}}$ & $2.93 \pm 0.15^{\mathrm{d}}$ \\
\hline Myricetine & $5.08 \pm 0.16^{\mathrm{a}}$ & $1.83 \pm 0.17^{\mathrm{d}}$ & $2.30 \pm 0.14^{\mathrm{c}}$ & $1.73 \pm 0.16^{\mathrm{d}}$ & $3.71 \pm 0.18^{b}$ & $2.12 \pm 0.19^{\mathrm{c}, \mathrm{d}}$ \\
\hline Quercetine & $3.23 \pm 0.13^{b}$ & $1.79 \pm 0.24^{\mathrm{c}, \mathrm{d}}$ & $1.25 \pm 0.03^{\mathrm{d}}$ & $1.69 \pm 0.23^{\mathrm{c}, \mathrm{d}}$ & $4.82 \pm 0.16^{\mathrm{a}}$ & $2.06 \pm 0.28^{c}$ \\
\hline Total flavonols & $58.15 \pm 1.31^{b}$ & $10.01 \pm 0.32^{\mathrm{c}}$ & $42.54 \pm 4.18^{\mathrm{b}}$ & $9.43 \pm 0.30^{c}$ & $86.84 \pm 4.22^{\mathrm{a}}$ & $11.55 \pm 0.36^{c}$ \\
\hline Piceatanol & $0.26 \pm 0.02^{b}$ & $0.08 \pm 0.01^{\mathrm{c}}$ & $0.20 \pm 0.01^{b}$ & $0.08 \pm 0.01^{c}$ & $0.57 \pm 0.04^{\mathrm{a}}$ & $0.27 \pm 0.03^{b}$ \\
\hline trans-Resveratrol & $4.85 \pm 1.03^{\mathrm{a}}$ & $0.84 \pm 0.06^{\mathrm{d}}$ & $2.10 \pm 0.15^{\mathrm{c}}$ & $0.79 \pm 0.08^{\mathrm{d}}$ & $3.37 \pm 0.25^{\mathrm{b}}$ & $0.82 \pm 0.06^{\mathrm{d}}$ \\
\hline Total stilbenes & $5.12 \pm 1.05^{\mathrm{a}}$ & $0.92 \pm 0.07^{\mathrm{c}}$ & $2.30 \pm 0.16^{\mathrm{b}}$ & $0.87 \pm 0.09^{c}$ & $3.94 \pm 0.29^{\mathrm{a}}$ & $1.09 \pm 0.09^{\mathrm{b}, \mathrm{c}}$ \\
\hline Total phenolic compounds (TPC) & $513.02 \pm 20.02^{\mathrm{a}}$ & $80.34 \pm 4.18^{\mathrm{c} . \mathrm{d}}$ & $294.87 \pm 11.47^{b}$ & $82.57 \pm 3.68^{\text {c.d }}$ & $245.31 \pm 12.02^{b}$ & $140.71 \pm 5.23^{c}$ \\
\hline
\end{tabular}

WR: white rum; MCW/MCM: carbonic maceration wine/must; AW/AM: aged wine/must; HEW/HEM: high expression wine/must. Concentration of polyphenolic compounds is expressed in $\mu \mathrm{g} \mathrm{mL}^{-1}$. 
related to the gut microflora, homovanillic acid (HV-Acid) and homovanillic alcohol (HV-Alc) (Table 1). The musts contained high amounts of HV-Acid, but lower contents of HV-Alc and a very low amount of OHTyr. HV-Alc followed a trend opposite to that of HV-Acid, its concentration increasing after winemaking for CMW and AW, but not for HEW (Table 1). The most important difference between the wines and musts was due to the increase in OHTyr after vinification $(p<0.05)$. As a result, HEW showed the highest OHTyr concentration of all the beverages $\left(35.11 \pm 2.51 \mu \mathrm{g} \mathrm{mL} \mathrm{m}^{-1}\right)$, followed by $\mathrm{AW}(29.65 \pm 0.46 \mu \mathrm{g}$ $\left.\mathrm{mL}^{-1}\right)$ and CMW $\left(16.13 \pm 2.98 \mu \mathrm{g} \mathrm{mL}^{-1}\right)$ (Table 1).

The concentrations found for every phenolic compound from wines and musts are shown in Table 2. Anthocyanins were the major phenolic compounds found in wines and musts. Among all the five anthocyanin glucosides, malvidin-3$O$-glucoside was the major anthocyanin both in wines and musts $(p<0.05)$. Moreover, delphinidin-3-O-glucoside and petunidin-3-O-glucoside were also prominent from the rest of the anthocyanins. The individual content of hydroxycinnamic acid derivatives was divided into two groups. Caftaric acid and coutaric acid were the major compounds, mainly found in wines. On the contrary, $p$-coumaric acid and fertaric acid were minor compounds in wine, being undetectable in must. The individual analysis of the different flavonols identified revealed quercetin-3-O-rutinoside and kaempferol-3-O-glucoside as major flavonols. Finally, trans-resveratrol was the main stilbene, both in wines and musts.

\section{Qualitative analysis of neuroprostanes and $\mathbf{F}_{2}$-dihomo-isopros- tanes in $24 \mathrm{~h}$ urine from healthy volunteers}

The NeuroPs and $\mathrm{F}_{2}$-dihomo-IsoPs analyzed are displayed in Table 3. In previous reports, the 4-series NeuroPs were selected to be the oxidative markers, due to their higher abundance in vivo. ${ }^{16,21}$ The 7- and 17-series are the major $\mathrm{F}_{2}$-dihomo-IsoP metabolites; thereby, they were chosen as the reference for the other oxidative markers of neurodegeneration in human urine samples. ${ }^{16,22}$ The NeuroPs and dihomo-IsoPs identified in the $24 \mathrm{~h}$ urine samples were as follows: $4(R)-\mathrm{F}_{4 \mathrm{t}}-\mathrm{NeuroP}$;

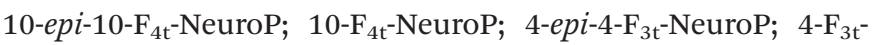
NeuroP; ent-7(R)-7- $\mathrm{F}_{2 \mathrm{t}}$-Dihomo-IsoP; ent-7-epi-7- $\mathrm{F}_{2 \mathrm{t}}$-Dihomo-IsoP;
17- $\mathrm{F}_{2 \mathrm{t}}$-Dihomo-IsoP and 17-epi-17- $\mathrm{F}_{2 \mathrm{t}}$-Dihomo-IsoP. These markers will help us to describe the neuroprotection capacity afforded by the intake of the different musts and wines in this study.

\section{Quantitative assessment of total neuroprostanes and $\mathbf{F}_{2^{-}}$ dihomo-isoprostanes in $\mathbf{2 4} \mathrm{h}$ urine from healthy volunteers}

As can be seen in Fig. 2, the mean values varied between treatments. The baseline (control) $24 \mathrm{~h}$ urinary concentration of total- $\mathrm{F}_{2}$-dihomo-IsoPs was $6.14 \pm 0.58 \mu \mathrm{g}$ per $24 \mathrm{~h}$, significantly higher $(p<0.01)$ than that found after the intake of the different musts. The treatment with the AM triggered the highest urinary concentration of total- $\mathrm{F}_{2}$-dihomo-IsoPs $(4.28 \pm$ $0.59 \mu \mathrm{g}$ per $24 \mathrm{~h})$, followed by the CMM $(3.97 \pm 0.67 \mu \mathrm{g}$ per $24 \mathrm{~h})$ and the primary must of HEM $(3.69 \pm 0.76 \mu \mathrm{g}$ per $24 \mathrm{~h})$. There were no significant differences among these values $(p>$ 0.05). However, the intake of CMW, AW, or HEW caused the urinary total- $\mathrm{F}_{2}$-dihomo-IsoPs $(2.53 \pm 0.64,2.96 \pm 0.45$ and $3.00 \pm 0.53 \mu \mathrm{g}$ per $24 \mathrm{~h}$, respectively) to be lower than the baseline value $(6.14 \pm 0.58 \mu \mathrm{g}$ per $24 \mathrm{~h})(p<0.05)$. It is of note, as observed for the must intake, that no differences in total- $\mathrm{F}_{2}$ dihomo-IsoPs existed among the red wine treatments $(p>$ 0.05). Concerning the alcohol content, the group consuming the alcohol equivalent to a serving of wine (WR) also had a concentration of urinary total- $\mathrm{F}_{2}$-dihomo-IsoPs $(4.95 \pm 0.82 \mu \mathrm{g}$ per $24 \mathrm{~h}$ ), which was significantly lower than that of the baseline group $(6.14 \pm 0.58 \mu \mathrm{g}$ per $24 \mathrm{~h})(p<0.05)$. However, the ingestion of WR resulted in significantly higher urinary concentrations of these total- $\mathrm{F}_{2}$-dihomo-IsoPs $(p<0.05)$ than the consumption of CMW, CMM, AW, HEW, or HEM.

The total amount of urinary NeuroPs found after the treatments varied widely (Fig. 2). The musts CMM and AM produced decreases $(p<0.05)$ in the urinary excretion of total NeuroPs, compared to the baseline concentration (4.78 \pm $0.72 \mu \mathrm{g}$ per $24 \mathrm{~h}$ ), while the intake of HEM exerted a particularly-marked protective effect $(p<0.01)$ against the generation of these compounds (total NeuroP concentration: $2.81 \pm$ $0.85 \mu \mathrm{g}$ per $24 \mathrm{~h}$ ). Regardless of the type, after the red wine intake the trend regarding the total NeuroP concentration was similar to that found after the ingestion of the different musts.

Table 3 Urinary neuroprostanes (NeuroPs) and $F_{2}$-dihomo-isoprostanes $\left(F_{2}\right.$-dihomo-IsoPs) after the treatments

\begin{tabular}{|c|c|c|c|c|c|c|c|c|c|}
\hline & & Control & WR & CMW & CMM & AW & $\mathrm{AM}$ & HEW & HEM \\
\hline & $4-e p i-4-\mathrm{F}_{3 \mathrm{t}}$ & $0.67 \pm 0.13$ & $0.51 \pm 0.11$ & $0.41 \pm 0.07$ & $0.52 \pm 0.19$ & $0.48 \pm 0.13$ & $0.62 \pm 0.21$ & $0.37 \pm 0.09$ & $0.46 \pm 0.08$ \\
\hline & $10-е p i-10-\mathrm{F}_{4 \mathrm{t}}$ & $0.95 \pm 0.24$ & $1.12 \pm 0.25$ & $0.89 \pm 0.18$ & $0.73 \pm 0.16$ & $0.64 \pm 0.28$ & $0.86 \pm 0.19$ & $0.60 \pm 0.17$ & $0.56 \pm 0.21$ \\
\hline & $10-\mathrm{F}_{4 \mathrm{t}}$ & $0.51 \pm 0.11$ & $0.85 \pm 0.32$ & $0.42 \pm 0.09$ & $0.36 \pm 0.10$ & $0.36 \pm 0.20$ & $0.39 \pm 0.17$ & $0.41 \pm 0.17$ & $0.37 \pm 0.24$ \\
\hline \multirow{2}{*}{$\mathrm{F}_{2}$-dihomo-IsoPs } & $17-$ epi-17- $\mathrm{F}_{2 \mathrm{t}}$ & $0.08 \pm 0.02$ & $0.05 \pm 0.01$ & $0.04 \pm 0.02$ & $0.04 \pm 0.01$ & $0.03 \pm 0.01$ & $0.05 \pm 0.02$ & $0.04 \pm 0.04$ & $0.04 \pm 0.02$ \\
\hline & $17-F_{2 t}$ & $0.70 \pm 0.10$ & $0.39 \pm 0.09$ & $0.31 \pm 0.13$ & $0.44 \pm 0.09$ & $0.25 \pm 0.10$ & $0.46 \pm 0.08$ & $0.28 \pm 0.12$ & $0.25 \pm 0.09$ \\
\hline
\end{tabular}

Means are expressed in $\mu \mathrm{g}$ per $24 \mathrm{~h}$. WR: white rum; MCW/MCM: carbonic maceration wine/must; AW/AM: aged wine/must; HEW/HEM: high expression wine/must. 


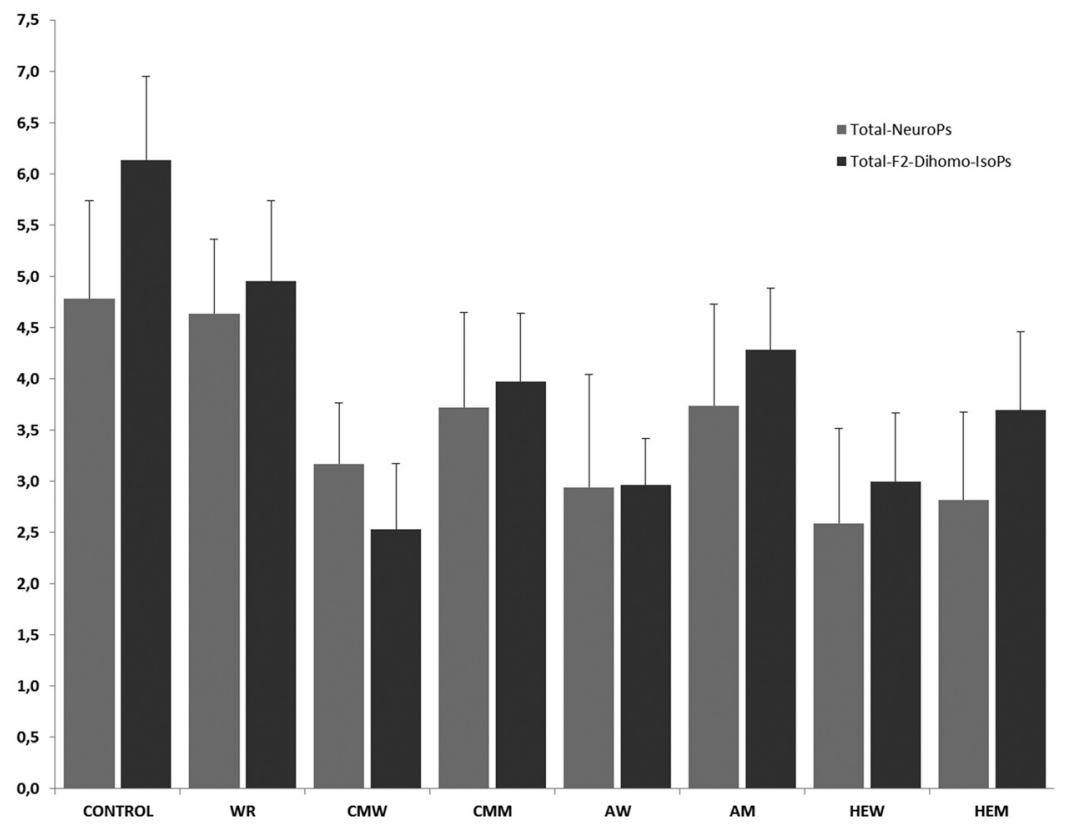

Fig. 2 Total neuroprostanes and $\mathrm{F}_{2}$-dihomo-isoprostanes. WR: white rum; MCW/MCM: carbonic maceration wine/must; AW/AM: aged wine/must; $\mathrm{HEW} / \mathrm{HEM}$ : high expression wine/must. The results are expressed as $\mu \mathrm{g}$ per $24 \mathrm{~h} \pm \mathrm{SD}$.

Therefore, the three types of wine exerted similar DHA protection $(p>0.05)$. Nevertheless, only after the HEW intake was significant $(p<0.01)$ diminution of the total NeuroP level detected; of the three wines, HEW provided the lowest urinary concentration $(3.17 \pm 0.59 \mu \mathrm{g}$ per $24 \mathrm{~h})$. Alcohol intake, represented by the treatment with white rum (WR), did not exert neuroprotection. In fact, urinary excretion of total NeuroPs after WR intake was similar $(4.64 \pm 0.95 \mu \mathrm{g}$ per $24 \mathrm{~h})$ to the baseline level. HEW and HEM intake, among CMM, also produced lower total NeuroP excretion $(p<0.05)$ than WR.

None of the three types of red wine exerted higher DHA protection against NeuroP production than their corresponding musts $(p<0.05)$. However, the high expression must and wine (HEM and HEW) were able to reduce the urinary excretion of total NeuroPs, indicating the influence of the cultivation and harvesting of the grapes and of the winemaking process on the final DHA protection capacity of the resultant must and, consequently, of the finished wine. The vinification process did not seem to influence the antiradical properties of the final red wine when measured as the total NeuroP concentration in urine, according to the only-slight differences between each must and its corresponding finished wine $(p>0.05)$.

\section{Quantitative assessment of individual neuroprostanes and} $\mathrm{F}_{2}$-dihomo-isoprostanes in $\mathbf{2 4} \mathrm{h}$ urine from healthy volunteers

The disparity among the individual NeuroPs and $\mathrm{F}_{2}$-dihomoIsoPs concerning their excretion after the intake of musts and wines was also detected (Table 3). The urinary concentrations of NeuroPs did not vary noticeably: in fact, NeuroPs such as 4-epi-4- $\mathrm{F}_{3 \mathrm{t}}, 4-\mathrm{F}_{3 \mathrm{t}}, 10-e p i-10-\mathrm{F}_{4 \mathrm{t}}$, and $10-\mathrm{F}_{4 \mathrm{t}}$ did not differ significantly among the distinct types of must and wine $(p>0.05)$.
Nevertheless, some findings can be highlighted. The main NeuroP found in urine was $4(R)-\mathrm{F}_{4 \mathrm{t}}$ (baseline of $2.40 \pm 0.19 \mu \mathrm{g}$ per $24 \mathrm{~h}$ ). Before must intake, the $4(R)-\mathrm{F}_{4 \mathrm{t}}$ excretion was lower than the baseline for all types of musts, significantly so $(p<0.05)$ in AM and HEM $(1.92 \pm 0.44 \mu \mathrm{g}$ per $24 \mathrm{~h}$ for CMM; $1.66 \pm 0.36 \mu \mathrm{g}$ per $24 \mathrm{~h}$ for AM and $1.20 \pm 0.26 \mu \mathrm{g}$ per $24 \mathrm{~h}$ for HEM) (Table 3). The intake of all three types of wine also led to a reduction of the urine concentration of $4(R)-\mathrm{F}_{4 \mathrm{t}}(p<0.05)$. The lowest value was found after HEW intake $(1.27 \pm$ $0.20 \mu \mathrm{g}$ per $24 \mathrm{~h}$ ). Besides, AW and CMW intake reduced the 4 $(R)-\mathrm{F}_{4 \mathrm{t}}$ concentration in urine to similar final values $(1.27 \pm$ $0.43 \mu \mathrm{g}$ per $24 \mathrm{~h}$ for AW and $1.02 \pm 0.17 \mu \mathrm{g}$ per $24 \mathrm{~h}$ for HEW) (Table 3).

Regarding the individual variation of $\mathrm{F}_{2}$-dihomo-IsoPs, the concentrations in urine differed widely after the intake of the different musts. The baseline levels of $17-$ epi-17- $\mathrm{F}_{2 \mathrm{t}}$ and $17-\mathrm{F}_{2 \mathrm{t}}$ in the urine were low $(0.08 \pm 0.02 \mu \mathrm{g}$ per $24 \mathrm{~h}$ and $0.70 \pm$ $0.10 \mu \mathrm{g}$ per $24 \mathrm{~h}$, respectively). After their administration to the healthy volunteers, CMM gave rise to urinary concentrations of both compounds that were similar to the baseline values $(p>0.05)(0.04 \pm 0.01 \mu \mathrm{g}$ per $24 \mathrm{~h}$ and $0.44 \pm 0.09 \mu \mathrm{g}$ per $24 \mathrm{~h}$, respectively), AM intake resulted in lower values $(p<0.05)$ for $17-e p i-17-\mathrm{F}_{2 \mathrm{t}}(0.05 \pm 0.02 \mu \mathrm{g}$ per $24 \mathrm{~h})$, and HEM intake produced a drop in the concentrations of 17-epi-17- $\mathrm{F}_{2 \mathrm{t}}$ $(0.04 \pm 0.012 \mu \mathrm{g}$ per $24 \mathrm{~h})$ and $17-\mathrm{F}_{2 \mathrm{t}}(0.25 \pm 0.09 \mu \mathrm{g}$ per $24 \mathrm{~h})$ (Table 3).

The highest baseline urinary concentrations were observed for ent-7(R)-7- $\mathrm{F}_{2 \mathrm{t}}(3.15 \pm 0.31 \mu \mathrm{g}$ per $24 \mathrm{~h})$ and ent-7-epi-7- $\mathrm{F}_{2 \mathrm{t}}$ $(2.21 \pm 0.35 \mu \mathrm{g}$ per $24 \mathrm{~h})$. The musts caused similar decreases in the ent $-7(R)-7-\mathrm{F}_{2 \mathrm{t}}$ and ent-7-epi-7- $\mathrm{F}_{2 \mathrm{t}}$ levels $(p>0.05)$. In fact, the ingestion of the musts significantly $(p<0.05)$ diminished 
the concentration of ent-7(R)-7- $\mathrm{F}_{2 \mathrm{t}}(1.85 \pm 0.35 \mu \mathrm{g}$ per $24 \mathrm{~h}$, $1.99 \pm 0.18 \mu \mathrm{g}$ per $24 \mathrm{~h}, 2.03 \pm 0.43 \mu \mathrm{g}$ per $24 \mathrm{~h}$ for MCM, $\mathrm{AM}$ and HEM intake, respectively). The urinary concentration of ent-7-epi-7- $\mathrm{F}_{2 \mathrm{t}}$ showed the same tendency, being lower after the intake of CMM $(1.64 \pm 0.22 \mu \mathrm{g}$ per $24 \mathrm{~h})$, AM $(1.79 \pm$ $0.32 \mu \mathrm{g}$ per $24 \mathrm{~h}$ ) and HEM (1.36 $\pm 0.22 \mu \mathrm{g}$ per $24 \mathrm{~h}$ ), compared to the baseline (Table 3 ). The wines also provoked decreases of

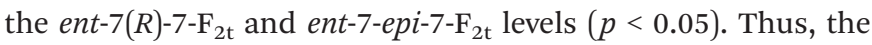
ent-7 $(R)-7-\mathrm{F}_{2 \mathrm{t}}$ excretion after CMW $(1.30 \pm 0.33 \mu \mathrm{g}$ per $24 \mathrm{~h})$, AW $(1.66 \pm 0.21 \mu \mathrm{g}$ per $24 \mathrm{~h})$, or HEW $(1.41 \pm 0.26 \mu \mathrm{g}$ per $24 \mathrm{~h})$ intake was markedly lower than the corresponding baseline value $(p<0.05)$. The urinary excretion of ent-7-epi-7- $\mathrm{F}_{2 \mathrm{t}}$ was $0.89 \pm 0.17 \mu \mathrm{g}$ per $24 \mathrm{~h}, 1.03 \pm 0.13 \mu \mathrm{g}$ per $24 \mathrm{~h}$ and $1.27 \pm$ $0.14 \mu \mathrm{g}$ per $24 \mathrm{~h}$ as a consequence of the administration of CMW, AW, and HEW, respectively (Table 3).

The dietary intake of alcohol (WR) reduced the concentration of ent-7(R)-7-F $\mathrm{F}_{2 \mathrm{t}}$ (to $2.4 \pm 0.6 \mu \mathrm{g}$ per $24 \mathrm{~h}$ ), compared with the baseline $(p<0.05)$. However, the urinary concentrations of the other $\mathrm{F}_{2}$-dihomo-IsoPs remained unchanged $(p>0.05)$ (Table 3$)$.

The winemaking processes did not influence the urinary concentration of individual NeuroPs: the differences observed between the musts and their respective wines were not significant $(p>0.05)$. Conversely, differences did occur for two urinary $\mathrm{F}_{2}$-dihomo-IsoPs. The urinary concentration of ent-7 $(R)-7-\mathrm{F}_{2 \mathrm{t}}$ was significantly higher $(p<0.05)$ after CMM intake than after CMW intake and the urinary concentration of ent-7-epi-7- $\mathrm{F}_{2 \mathrm{t}}$ after the intake of $\mathrm{AM}$ was higher than after the intake of $\mathrm{AW}$, highlighting the importance of the vinification process and the new compounds formed which boosted these effects on these markers.

\section{Discussion}

In recent years, polyphenols have been related to the beneficial effects on human health upon moderate consumption of red wine. ${ }^{7,23,24}$ Among others, they have been attributed to antioxidant $^{18}$ anti-inflammatory ${ }^{8}$ and anticancer properties. ${ }^{25,26}$ Polyphenols exert neuroprotective effects; ${ }^{23}$ especially, anthocyanins have also been reported to be able to trespass the blood brain barrier. ${ }^{27}$ Finally, they have antiatherogenic and anti-inflammatory effects and vasodilator capacity, and show cardioprotective properties. ${ }^{8}$

Despite the health effects of polyphenols on humans, the scientific literature shows a very low bioavailability. ${ }^{28-30}$ Therefore, despite the antioxidant capacity of the polyphenols and the importance of these compounds in the wine and grape matrices, their low absorption appears to be a limiting factor when considering the intake of polyphenols as key factor in the antioxidant effects of red wine. In our study, the intake of unique polyphenols (OHTyr and total polyphenols) not including colon derivatives (only OHTyr microflora metabolites) - has been approached in order to determine their preventive effect on lipid peroxidation. However, anthocyanins, being the major polyphenol in wine and must, have been demonstrated to be directly absorbed in the intestine. ${ }^{31}$ Moreover, other newly reported bioactive compounds in wine and must called phytoprostanes have shown healthy benefits regarding oxidative injury prevention and anti-inflammatory capacity. In fact, they have been reported to have absorption in the intestine although colonic metabolites have not yet been reported. ${ }^{3,32}$ Therefore, this work is a preliminary study that may help to understand the role of certain wine compounds in the oxidation of DHA, EPA and AdA.

Red wine has shown in vivo neuroprotective effects, mainly attributed to its polyphenolic composition and its antioxidant properties. $^{23,33}$ As mentioned above, MEL and OHTyr can act as local antioxidants due to their capacity to traverse physiological barriers. ${ }^{10,34}$ To elucidate if MEL or OHTyr could be, at least partly, responsible for the observed neuroprotective effects of red wine, a regression study was carried out.

The results of regression analysis performed for the urinary excretion of total NeuroPs and total $\mathrm{F}_{2}$-dihomo-IsoPs are given in Table 4. As can be appreciated, the simple regression study shows that the excretion of NeuroPs is individually mainly explained by OHTyr intake (responsible for $15.5 \%$ of the observed variation). Meanwhile, the intake of MEL, HV-Acid, HV-Alc and TPC was responsible for $13.5 \%, 0.3 \%, 7.2 \%$ and $4.4 \%$ of the observed variation in the urinary excretion of NeuroPs, respectively. Finally, multiple regression analysis following the same trend was performed after simple regression, which showed little statistical weight for all compounds present in musts and wines. Only $23.6 \%$ of the observed change in the excretion of NeuroPs can be explained by the statistical model containing all the bioactive compounds and TPC simultaneously. This same model showed that the intake of OHTyr explains $16.5 \%$ of the observed change in the NeuroP variation, taking into account all the compounds included in the beverages. Therefore, it is clear that the excretion of NeuroPs must be influenced by various factors

Table 4 Determination coefficients derived from the study of simple regression and multiple regression of the urinary excretion of total neuroprostanes and $\mathrm{F}_{2}$-dihomo-isoprostanes

\begin{tabular}{lll}
\hline & Total NeuroPs & Total $\mathrm{F}_{2}$-dihomo-IsoPs \\
\hline Simple regression $\left(R^{2}\right)$ & & \\
MEL & 0.135 & 0.439 \\
OHTyr & 0.155 & 0.207 \\
HV-Acid & 0.003 & 0.080 \\
HV-Alc & 0.072 & 0.331 \\
TPC & 0.044 & 0.327 \\
Multiple regression & & \\
$R^{2}$ Tot. & 0.236 & 0.441 \\
$R^{2}$ Select. & 0.165 (OHTyr) & 0.439 (MEL)
\end{tabular}

MEL: melatonin; OHTyr: hydroxytyrosol; HV-Acid: homovanillic acid; HV-Alc: homovanillic alcohol; TPC: total phenolic compounds. $R^{2}$ Tot.: coefficient of regression which expresses the statistical significance of all the compounds studied with respect to each biomarker. $R^{2}$ Select.: coefficient of determination of compounds selected by the statistical robustness model. All these values are treated as \% of influence on the final concentration. 
that cannot be determined in the present study. However, the intake of the various compounds (especially OHTyr) may be partially responsible for the decrease in the excretion of urinary NeuroPs.

The simple regression in relation to the excretion of $\mathrm{F}_{2}$ dihomo-IsoPs showed a greater influence of the different compounds contained in the beverages than discussed above for the urinary excretion of NeuroPs. By conducting the study of simple regression, the urinary excretion of $\mathrm{F}_{2}$-dihomo-IsoPs is explained in $43.9 \%$ by the intake of MEL, in $20.7 \%$ by OHTyr, in $8 \%$ by HV-Acid, in $33.1 \%$ by HV-Alc and in $32.7 \%$ by TPC. Moreover, the study of multiple regression showed that the observed variation in the excretion of $\mathrm{F}_{2}$-dihomo-IsoPs is explained in $44.1 \%$ by the whole compounds studied simultaneously. Overall, the intake of MEL was the most significant describing the observed variation, explaining $43.9 \%$ of the observed decrease in the urinary excretion of $\mathrm{F}_{2}$-dihomoIsoPs.

The scientific literature about neuroprostanes and $\mathrm{F}_{2}$ dihomo-isoprostanes is still limited to a few description and synthesis papers. The description of neuroprostanes and $\mathrm{F}_{2}$-dihomo-isoprostanes in human fluids is restricted to physiopathological conditions such as Rett syndrome, brain injury or Alzheimer disease among others. ${ }^{35-39}$ Some studies have reported the reduction of other lipid peroxidation biomarkers as isoprostanes. ${ }^{40}$ However, it is not relevant in the present study due to the general location in the human body. Other studies reported a notable reduction in lipid peroxidation related to the central nervous system in young adult triathletes, showing similar values to those reported in the present study. García-Flores et al. reported that one serving of fruit juice rich in polyphenols leads to minor urinary excretion of neuroprostanes and dihomo-isoprostanes. ${ }^{41}$ They related those changes observed to the content of polyphenols of the fruit beverages. Therefore, the comparison of the physiological levels of the biomarkers with previous scientific literature is still limited in the case of a healthy population.

Therefore, all the bioactive compounds taken into account in this research study including TPC seem to exert neuroprotection. On one hand, MEL appears to exert its neuroprotective effect by the oxidative protection of AdA, measured by the formation of $\mathrm{F}_{2}$-dihomo-IsoPs. Meanwhile, OHTyr has proved to be responsible for the protection of DHA against oxidative species, determined by the measurement of the total production of NeuroPs.

According to the above statistical analysis, the differences observed among the wine and must treatments could be related to their MEL contents. The CMW, in which the concentration of MEL was the highest $\left(161.83 \pm 7.1 \mathrm{ng} \mathrm{mL}^{-1}\right)$, was the only wine that gave a significantly greater decrease in total urinary $\mathrm{F}_{2}$-dihomo-IsoPs compared to its preceding must, CMM $(p=0.015)$. Taking into account these results, the fact that MEL can act as an antioxidant and its ability to cross the $\mathrm{BBB}$, it is evident that MEL in wine must be considered with neuro-protection capacity. ${ }^{10}$ In particular, the decrease in urinary $\mathrm{F}_{2}$-dihomo-IsoPs, compared to the baseline level, is representative of protection of the white brain matter against oxidative stress. ${ }^{5}$ The effects of wine on lipid peroxidation have been found to result in a decrease in the production of oxidized compounds. ${ }^{40,42}$ Nonetheless, to the best of our knowledge, no reports about MEL or OHTyr and NeuroPs or $\mathrm{F}_{2}$-dihomo-IsoPs have been published. Therefore, this is the first in vivo assay of the relationship between the intake of these bioactive molecules as part of wine and neuroprotection.

There are few reports on the urinary excretion of $\mathrm{F}_{4}$-NeuroPs and $\mathrm{F}_{2}$-dihomo-IsoPs. However, similar results in urine were obtained using UHPLC-QqQ-MS/MS, ${ }^{16}$ reporting $3.30 \pm 1.17 \mu \mathrm{g} \mathrm{mL} \mathrm{m}^{-1}$ for NeuroPs and $6.12 \pm 1.51 \mu \mathrm{g} \mathrm{mL} \mathrm{m}^{-1}$ for $\mathrm{F}_{2}$-dihomo-IsoPs as mean values in a healthy population. Meanwhile, in epileptic patients there was greater degradation of neuronal membranes and myelin, giving mean values of $5.51 \pm 1.86 \mu \mathrm{g} \mathrm{mL} \mathrm{m}^{-1}$ for NeuroPs and $7.81 \pm 1.87 \mu \mathrm{g} \mathrm{mL} \mathrm{m}^{-1}$ for $\mathrm{F}_{2}$-dihomo-IsoPs. The urinary excretion of $\mathrm{F}_{4}$-NeuroPs and $\mathrm{F}_{2}$-dihomo-IsoPs was also studied in healthy subjects after the intake of a citrus-based juice, ${ }^{14}$ showing slightly higher values than those reported in the present study.

Additionally, NeuroPs and $\mathrm{F}_{2}$-dihomo-IsoPs have been described in other biological fluids such as plasma and cerebrospinal fluid. Other authors ${ }^{35}$ described a plasmatic increase of $\mathrm{F}_{4}$-NeuroPs in patients with Rett syndrome, compared to healthy subjects. Similarly, Durand et al. $(2013)^{5}$ and De Felice, Signorini, Durand, Oger, Guy, Bultel-Poncé et al. $(2011)^{36}$ found higher plasmatic levels of $\mathrm{F}_{2}$-dihomo-IsoPs in Rett syndrome patients. Finally, the cerebrospinal fluid content of $\mathrm{F}_{4}$-NeuroPs and $\mathrm{F}_{2}$-dihomo-IsoPs has also been reported, showing an increment of both biomarkers in many diseases such as brain injury, Alzheimer's disease, or aneurysmal subarachnoid hemorrhage. ${ }^{37-39}$

As expected, the vinification processes enhanced the neuroprotective effect of the wines, with regard to total- $\mathrm{F}_{2}$-dihomoIsoPs, in comparison with the musts. ${ }^{34}$ In general, unless not statistically significant $(p>0.05)$, red wine intake resulted in a greater decrease of $24 \mathrm{~h}$ total $\mathrm{F}_{2}$-dihomo-IsoP excretion than the must intake did.

\section{Conclusions}

Red wine intake reduces oxidative injury in the central nervous system to a greater extent than must and ethanol intake, measured by the urinary excretion of neuroprostanes and $\mathrm{F}_{2}$-dihomo-isoprostanes. Melatonin may be the bioactive compound that better explains the increase in the percentage of protection against the oxidative attack of AdA, judged by the reduction in the formation of $\mathrm{F}_{2}$-dihomo-isoprostanes and their subsequent urinary excretion. Similarly, hydroxytyrosol may explain the increase in the protection of DHA and EPA from oxidative attack, measured by the reduction in the formation of $\mathrm{F}_{3}$-neuroprostanes and $\mathrm{F}_{4}$-neuroprostanes respectively.

Consequently, the intake of CMW containing high quantities of melatonin and hydroxytyrosol could develop an 
increased reduction of oxidative injury compared to aged wines (AW and HEW). However, only hydroxytyrosol metabolites have been approached in the present study. Therefore, further studies may help to understand the effect of other bioactive compounds such as polyphenol's colon derivatives and newly discovered phytoprostanes on reducing central nervous system lipid peroxidation.

\section{Author contribution}

Javier Marhuenda carried out the analytical processes and wrote and discussed the present paper. Sonia Medina supervised the analytical processes and developed the discussion of the paper. Pedro Martinez-Hernández and Simón Arina provided the beverages of the study and supervised the article. Pilar Zafrilla and Juana Mulero developed the randomized controlled trial. Camille Oger, Jean-Marie Galano and Thierry Durand provided the markers for the study and helped with the review of the manuscript. Federico Ferreres helped with the experimental procedures linked to UHPLC-QqQ-MS/MS. Ángel Gil-Izquierdo and Sonia Medina designed, supervised, and discussed this research work.

\section{Conflict of interest}

The authors declare that there is no conflict of interest associated with this manuscript.

\section{Acknowledgements}

This work has been partially funded by the "Fundación Séneca de la Región de Murcia” Grupo de Excelencia 19900/GERM/15. The authors are grateful to UCAM for the support bridged during the development of the assay for the study. Sonia Medina is grateful to the CICYT for a research contract (AGL2011-23690). Finally, the authors want to thank David Walker as an English Expert Reviewer and Jose Miguel Martínez-Sanz for providing information about melatonin intake in the Mediterranean diet.

\section{References}

1 S. Medina, R. Domínguez-Perles, J. I. Gil, F. Ferreres, C. García-Viguera, J. M. Martínez-Sanz and A. Gil-Izquierdo, A ultra-pressure liquid chromatography/triple quadrupole tandem mass spectrometry method for the analysis of 13 eicosanoids in human urine and quantitative 24 hour values in healthy volunteers in a controlled constant diet, Rapid Commun. Mass Spectrom., 2012, 26, 1249-1257.

2 E. Miller, A. Morel, L. Saso and J. Saluk, Isoprostanes and neuroprostanes as biomarkers of oxidative stress in neurodegenerative diseases, Oxid. Med. Cell. Longevity, 2014, 2014, 572491.
3 J. Marhuenda, S. Medina, A. Díaz-Castro, P. MartínezHernández, S. Arina, P. Zafrilla, J. Mulero, C. Oger, J.-M. Galano, T. Durand, F. Ferreres and A. Gil-Izquierdo, Dependency of Phytoprostane Fingerprints of Must and Wine on Viticulture and Enological Processes, J. Agric. Food Chem., 2015, 63, 9022-9028.

4 S. Medina, R. Domínguez-Perles, R. Cejuela-Anta, D. Villaño, J. M. Martínez-Sanz, P. Gil, C. García-Viguera, F. Ferreres, J. I. Gil and A. Gil-Izquierdo, Assessment of oxidative stress markers and prostaglandins after chronic training of triathletes, Prostaglandins Other Lipid Mediators, 2012, 99, 79-86.

5 T. Durand, C. De Felice, C. Signorini, C. Oger, V. BultelPoncé, A. Guy, J. M. Galano, S. Leoncini, L. Ciccoli, A. Pecorelli, G. Valacchi and J. Hayek, F2-Dihomo-isoprostanes and brain white matter damage in stage 1 Rett syndrome, Biochimie, 2013, 95, 86-90.

6 R. F. Guerrero, M. C. García-Parrilla, B. Puertas and E. Cantos-Villar, Wine, resveratrol and health: A review, Nat. Prod. Commun., 2009, 4, 635-658.

7 S. Renaud and M. De Lorgeril, Wine, alcohol, platelets, and the French paradox for coronary heart disease, Lancet, 1992, 339, 1523-1526.

8 A. A. A. Bertelli and D. K. Das, Grapes, wines, resveratrol, and heart health, J. Cardiovasc. Pharmacol., 2009, 54, 468-476.

9 A. Gil-Izquierdo, P. Zafrilla and F. A. Tomás-Barberán, An in vitro method to simulate phenolic compound release from the food matrix in the gastrointestinal tract, Eur. Food Res. Technol., 2002, 214, 155-159.

10 M. I. Fernández-Mar, R. Mateos, M. C. García-Parrilla, B. Puertas and E. Cantos-Villar, Bioactive compounds in wine: Resveratrol, hydroxytyrosol and melatonin: A review, Food Chem., 2012, 130, 797-813.

11 S. Lafay and A. Gil-Izquierdo, Bioavailability of phenolic acids, Phytochem. Rev., 2008, 7, 301-311.

12 M. Iriti, E. M. Varoni and S. Vitalini, Melatonin in traditional Mediterranean diets, J. Pineal Res., 2010, 49, 101-105.

13 E. Miller, A. Morel, L. Saso and J. Saluk, Melatonin Redox Activity. Its Potential Clinical Applications in Neurodegenerative Disorders, Curr. Top. Med. Chem., 2015, 15, 163-169.

14 L. A. García-Flores, S. Medina, R. Cejuela, J. M. MartínezSanz, C. Oger, J.-M. Galano, T. Durand, T. Casas-Pina, P. Martínez-Hernández, F. Ferreres and Á. Gil-Izquierdo, Assessment oxidative stress biomarkers-neuroprostanes and dihomo-isoprostanes-in elite triathletes urine after two weeks of moderate altitude training, Free Radical Res., 2016, 1-24.

15 J. Marhuenda, S. Medina, P. Martínez-Hernández, S. Arina, P. Zafrilla, J. Mulero, H.-G. Genieser, F. Ferreres and Á. GilIzquierdo, Melatonin and hydroxytyrosol-rich wines influence the generation of DNA oxidation catabolites linked to mutagenesis after the ingestion of three types of wine by healthy volunteers, Food Funct., 2016, DOI: 10.1039/ C6FO01246A. 
16 S. Medina, I. De Miguel-Elízaga, C. Oger, J.-M. Galano, T. Durand, M. Martínez-Villanueva, M. L. Gil-Del Castillo, I. Villegas-Martínez, F. Ferreres, P. Martínez-Hernández and Á. Gil-Izquierdo, Dihomo-isoprostanes -non-enzymatic metabolites of AdA- are higher in epileptic patients compared to healthy individuals by a new UHPLC-QqQ-MS/MS method, Free Radicals Biol. Med., 2015, 79, 154-163.

17 E. Cantos, J. C. Espín, M. J. Fernández, J. Oliva and F. A. Tomás-Barberán, Postharvest UV-C-irradiated grapes as a potential source for producing stilbeneenriched red wines, J. Agric. Food Chem., 2003, 51, 12081214.

18 J. Mulero, P. Zafrilla, J. M. Cayuela, A. Martínez-Cachá and F. Pardo, Antioxidant activity and phenolic compounds in organic red wine using different winemaking techniques, J. Food Sci., 2011, 76, 436-440.

19 R. Domínguez-Perles, D. Auñón, F. Ferreres and A. Gil-Izquierdo, Gender Differences on Plasma and Urine metabolites from Sprague-dawley Rats after Oral Administration of Normal and High Dose of Hydroxytyrosol, Hydroxytyrosol Acetate, and DOPAC., Eur. J. Nutr., 2015, DOI: 10.1007/s00394-015-1071-2.

20 M. S. Fernández-Pachón, S. Medina, G. Herrero-Martín, I. Cerrillo, G. Berná, B. Escudero-López, F. Ferreres, F. Martín, M. C. García-Parrilla and A. Gil-Izquierdo, Alcoholic fermentation induces melatonin synthesis in orange juice, J. Pineal Res., 2014, 56, 31-38.

21 H. Yin, E. S. Musiek, L. Gao, N. A. Porter and J. D. Morrow, Regiochemistry of neuroprostanes generated from the peroxidation of docosahexaenoic acid in vitro and in vivo, J. Biol. Chem., 2005, 280, 26600-26611.

22 M. Vanrollins, R. L. Woltjer, H. Yin, J. D. Morrow and T. J. Montine, F 2-Dihomo-isoprostanes arise from free radical attack on adrenic acid, J. Lipid Res., 2008, 49, 9951005.

23 A. Basli, S. Soulet, N. Chaher, J. M. Mérillon, M. Chibane, J. P. Monti and T. Richard, Wine polyphenols: Potential agents in neuroprotection, Oxid. Med. Cell. Longevity, 2012, 2012, 805762.

24 S. C. Renaud, A. D. Beswick, A. M. Fehily, D. S. Sharp and P. C. Elwood, Alcohol and platelet aggregation: The Caerphilly Prospective Heart Disease Study, Am. J. Clin. Nutr., 1992, 55, 1012-1017.

25 A. Artero, A. Artero, J. J. Tarín and A. Cano, The impact of moderate wine consumption on health, Maturitas, 2015, 80, 3-13.

26 M. Kampa, A. Hatzoglou, G. Notas, A. Damianaki, E. Bakogeorgou, C. Gemetzi, E. Kouroumalis, P.-M. Martin and E. Castanas, Wine antioxidant polyphenols inhibit the proliferation of human prostate cancer cell lines, Nutr. Cancer, 2000, 37, 223-233.

27 S. Schaffer and B. Halliwell, Do polyphenols enter the brain and does it matter? Some theoretical and practical considerations, Genes Nutr., 2012, 7, 99-109.
28 J. Bouayed, H. Deußer, L. Hoffmann and T. Bohn, Bioaccessible and dialysable polyphenols in selected apple varieties following in vitro digestion vs. their native patterns, Food Chem., 2012, 131, 1466-1472.

29 J. Bouayed, L. Hoffmann and T. Bohn, Total phenolics, flavonoids, anthocyanins and antioxidant activity following simulated gastro-intestinal digestion and dialysis of apple varieties: Bioaccessibility and potential uptake, Food Chem., 2011, 128, 14-21.

30 D. Tagliazucchi, E. Verzelloni, D. Bertolini and A. Conte, In vitro bio-accessibility and antioxidant activity of grape polyphenols, Food Chem., 2010, 120, 599-606.

31 S. Talavéra, C. Felgines, O. Texier, C. Besson, A. GilIzquierdo, J.-L. Lamaison and C. Rémésy, Anthocyanin metabolism in rats and their distribution to digestive area, kidney, and brain, J. Agric. Food Chem., 2005, 53, 39023908.

32 A. E. Barden, K. D. Croft, T. Durand, A. Guy, M. J. Mueller and T. A. Mori, Flaxseed oil supplementation increases plasma F1-phytoprostanes in healthy men, J. Nutr., 2009, 139, 1890-1895.

33 M. P. Gómez-Serranillos, S. Martín, T. Ortega, O. M. Palomino, M. Prodanov, V. Vacas, T. Hernández, I. Estrella and M. E. Carretero, Study of red wine neuroprotection on astrocytes, Plant Foods Hum. Nutr., 2009, 64, 238-243.

34 M. I. Rodríguez-Naranjo, A. Gil-Izquierdo, A. M. Troncoso, E. Cantos-Villar and M. C. Garcia-Parrilla, Melatonin is synthesised by yeast during alcoholic fermentation in wines, Food Chem., 2011, 126, 1608-1613.

35 C. Signorini, C. De Felice, S. Leoncini, A. Giardini, M. D'Esposito, S. Filosa, F. Della Ragione, M. Rossi, A. Pecorelli, G. Valacchi, L. Ciccoli and J. Hayek, F4-neuroprostanes mediate neurological severity in Rett syndrome, Clin. Chim. Acta, 2011, 412, 1399-1406.

36 C. De Felice, C. Signorini, T. Durand, C. Oger, A. Guy, V. Bultel-Poncé, J. M. Galano, L. Ciccoli, S. Leoncini, M. D’Esposito, S. Filosa, A. Pecorelli, G. Valacchi and J. Hayek, F2-dihomo-isoprostanes as potential early biomarkers of lipid oxidative damage in Rett syndrome, J. Lipid Res., 2011, 52, 2287-2297.

37 Y. P. Hsieh, C. L. Lin, A. L. Shiue, H. Yin, J. D. Morrow, J. C. Hsu, T. C. Hsieh, H. J. Wei and H. C. Yen, Correlation of F4-neuroprostanes levels in cerebrospinal fluid with outcome of aneurysmal subarachnoid hemorrhage in humans, Free Radicals Biol. Med., 2009, 47, 814-824.

38 H. C. Kuo, H. C. Yen, C. C. Huang, W. C. Hsu, H. J. Wei and C. L. Lin, Cerebrospinal fluid biomarkers for neuropsychological symptoms in early stage of lateonset Alzheimer's disease, Int. J. Neurosci., 2015, 125, 747-754.

39 H. C. Yen, T. W. Chen, T. C. Yang, H. J. Wei, J. C. Hsu and C. L. Lin, Levels of F2-isoprostanes, F4-neuroprostanes, and total nitrate/nitrite in plasma and cerebrospinal fluid of patients with traumatic brain injury, Free Radical Res., 2015, 49, 1419-1430. 
40 I. C. Schrieks, R. van den Berg, A. Sierksma, J. W. J. Beulens, W. H. J. Vaes and N. F. J. Hendriks, Effect of red wine consumption on biomarkers of oxidative stress, Alcohol Alcohol., 2013, 48, 153-159.

41 L. A. García-Flores, S. Medina, C. Oger, J.-M. Galano, T. Durand, R. Cejuela, J. M. Martínez-Sanz, F. Ferreres and A. Gil-Izquierdo, Lipidomic approach in young adult triathletes: effect of supplementation with a poly- phenols-rich juice on neuroprostane and $\mathrm{F}$ 2-dihomoisoprostane markers, Food Funct., 2016, 7, 43434355.

42 P. Pignatelli, A. Ghiselli, B. Buchetti, R. Carnevale, F. Natella, G. Germanò, F. Fimognari, S. Di Santo, L. Lenti and F. Violi, Polyphenols synergistically inhibit oxidative stress in subjects given red and white wine, Atherosclerosis, 2006, 188, 77-83. 